\title{
El Grupo del Banco Mundial, el FMI y los derechos humanos: Sobre las obligaciones directas y la atribución de la conducta ilícita
}

\author{
The World Bank Group, the IMF and Human \\ Rights: about Direct Obligations and the \\ Attribution of Unlawful Conduct
}

\section{Willem van Genugten 1 Universidad de Tilburg, Países Bajos}

Revista Derechos en Acción ISSN 2525-1678/ e-ISSN 2525-1686

Año 6/No 18 Verano 2020-2021 (21 diciembre a 20 marzo), 130-172

DOl: https://doi.org/10.24215/25251678e480

Resumen: El objetivo principal del artículo es puntualizar cuáles de las normas presentes en la normativa internacional en materia de derechos humanos son aplicables al Grupo del Banco Mundial (GBM) y al Fondo Monetario Internacional (FMI), así como los puntos específicos en que pueden atribuirseles responsabilidad por violación a esas normas. Después de analizar cómo se posicionan tanto el GBM como el FMl

\footnotetext{
1 Profesor emérito de Derecho Internacional en la Universidad de Tilburg (Holanda) y profesor de Derecho Internacional en la Universidad North-West (Sudáfrica).

Este artículo fue parte de un proyecto más grande y fruto de la cooperación dedicada de un grupo de personas, en especial Wolfgang Benedek, Josh Curtis, Charline Daelman, Asbjørn Eide, Mary Footer, Ana Sofía Freitas de Barros, Tara van Ho, Yannick Radi, Cedric Ryngaert, Anne Vandenbogaerde y Wouter Vandenhole. Este artículo fue publicado en inglés en Wouter Vandenhole (ed.), Challenging Territoriality in Human Rights Law. Building Blocks for a Plural and Diverse Duty-Bearer Regime, (Routledge, 2015), 44-68. La traducción al español fue realizada por Natalia Barry y Michael Dwerryhouse. También se puede consultar el siguiente libro del autor, con secciones amplias sobre responsabilidad y reparación y los Principios Rectores del grupo del Banco Mundial, el FMI y los derechos humanos: The World Bank Group, the IMF and Human Rights: A Contextualised Way Forward, (Intersentia, 2015).
} 
en el ámbito de los derechos humanos (apartado 2), se discuten las numerosas capas de responsabilidades primordiales que pueden aplicarse (apartado 3). A estas secciones, les sigue un tratamiento extenso sobre la atribución de conductas ilícitas a las instituciones financieras internacionales (IFI) y sus Estados miembros, donde se analizan conceptos como "responsabilidad principal" y "secundaria", así como las consecuencias legales de "tener control" (apartado 4). El artículo podría haber puesto más alta la vara de las obligaciones legales y de las responsabilidades correspondientes para ambas IFI, por ejemplo, mediante la presentación de interpretaciones más extensas de jurisprudencia ya existente. Sin embargo, un análisis de tales características no sería realista, dadas las situaciones complejas en que tienen que funcionar habitualmente ambas IFI. Es mejor considerar la normativa referente a los derechos humanos como una forma de derecho vivo: ambas IFI han atravesado el umbral de los derechos humanos, en diferentes grados, y están en condiciones de ser confrontadas de manera sólida para que den el siguiente paso.

Abstract: The key aim of the article/chapter is to make clear what international human rights norms apply to the World Bank Group (WBG) and the International Monetary Fund (IMF) and to specify points for coining their responsibility for the violations of such norms. After having discussed the way both the WBG and the IMF position themselves in the human rights field (part $\mathrm{x}$ ), the article/chapter discusses several layers of applicable substantive human rights obligations (part x), followed by an extensive treatment of the attribution of unlawful conduct to both International Financial Institutions (IFIs) and their member states, including concepts such as 'primary' and 'secondary responsibility' and the legal consequences of 'being in control' (part x). The article could have set the legal obligations and the corresponding responsibilities for both IFIs higher, for instance by presenting more extensive interpretations of already existing case-law, but that would according to the author not be realistic, given the complex situations within which both IFls regularly have to function. According to the author, human rights law is best to be seen as living law: both IFls have entered the human-rights-doorway, be it to different degrees, and can solidly be confronted with new steps ahead 


\section{Introducción}

¿El GBM y el FMI están obligados a cumplir con el derecho internacional de los derechos humanos? Para algunos/as, como el exsecretario general de la ONU, Kofi Annan, no hay duda alguna: "La promoción de los derechos humanos no debe abordarse como si se tratara de una cuestión separada de [...] otras actividades [que lleva a cabo la ONU]. Por el contrario, es el hilo conductor que las atraviesa a todas [...]". ${ }^{2}$ Se trata de la "transversalización (mainstreaming) de los derechos humanos". En este abordaje, el concepto de derechos humanos se usa como puente o como "pieza de engranaje" en la lucha contra la (sobre) fragmentación del derecho internacional, y también como "estrella guía" - tal vez la única - para la tan compleja y diversa organización que es Naciones Unidas. Este enfoque incluiría a los principales organismos de la ONU y a todas las organizaciones internacionales, así como a los órganos especializados vinculados con ella como, en el contexto del presente artículo, el GBM y el FMI. Sin embargo, otros/as proponen que deben observarse las cartas orgánicas y demás documentos constitutivos de ambas Instituciones Financieras Internacionales (IFI), al igual que sus especializaciones. El corolario de esta línea de pensamiento es que lo deseable (o hasta obligatorio) sería colocar estos documentos constitutivos por encima $-\mathrm{O}$, al menos, a igual nivel- que las demás obligaciones internacionales que tienen las IFI en virtud de su vínculo con "la familia ONU". ${ }^{3}$ Las dos miradas vuelven una y otra vez sobre el análisis de por qué y hasta qué punto el GBM y el FMI estarían legalmente obligados a respetar la normativa de derechos humanos. El objetivo principal de este artículo es clarificar las normas internacionales en materia de derechos humanos que concretamente obligan al GBM y al FMI, y así identificar y especificar las situaciones en

2 Organización de las Naciones Unidas, Memoria del Secretario General sobre la labor de la Organización, (Nueva York, 1998), 23.

3 J. Oloka-Onyango y Deepika Udagama, Documento de la ONU, E/CN.4/Sub.2/11, 14. 
las que deban asumir responsabilidad por la violación de dichas normas. Respecto a lo último, el foco está en los principios y conceptos que pueden ayudar a atribuir las conductas ilícitas y asignar la responsabilidad correspondiente a cada involucrado, ya sea compartida o no con sus Estados miembros. ${ }^{4}$

Para empezar, el apartado 2 del presente artículo aborda la forma en que el GBM y el FMI identifican, por sí mismos, la superposición de su respectivo ámbito de operación con algunas cuestiones referentes a los derechos humanos. Luego, en el apartado 3, se profundiza el tema de las obligaciones de ambas IFI y sus Estados miembros en materia de derechos humanos. En el apartado 4 se analiza la responsabilidad de las IFI y sus Estados miembros frente a violaciones a los derechos humanos. Por último, el apartado 5 presenta algunos comentarios a modo de conclusión.

\section{Las IFI y su postura en el ámbito de los derechos humanos}

Antes de abordar los requerimientos que se desprenden del derecho internacional de los derechos humanos respecto

4 Se propone un breve análisis de la terminología usada en el presente artículo. El "Proyecto de artículos sobre la responsabilidad del Estado por hechos internacionalmente ilícitos", elaborado en 2001, usa el término "atribución de una conducta" en referencia a un Estado y otras variantes (artículo 2, título del capítulo Il y artículos 10 y 11). Por su parte, los "Proyectos de artículos sobre la responsabilidad del Estado por hechos internacionalmente ilícitos", también del 2011, hacen lo propio en referencia a las organizaciones internacionales (artículo 4, título del capítulo II y artículo 9). Por otro lado, los Principios de Maastricht sobre las Obligaciones Extraterritoriales (ETO, por su sigla en inglés) del 2012, se refieren a la "[a]tribución de responsabilidad al Estado por la conducta de..." (título del Principio 12), mientras que el Principio 11 estipula que "la responsabilidad del Estado se genera como resultado de conductas atribuibles a un Estado...". En mi abordaje postulo que, primero, deben verificarse los hechos; el siguiente paso es ver si estos revelan violaciones a los derechos humanos y, en caso afirmativo, cuál o cuáles puntualmente; el tercer paso es establecer quién tiene la responsabilidad de estas violaciones y tendría que aceptar sus consecuencias. Por estas razones, recurro a frases como "conceptos que puedan ayudar a identificar las conductas ilícitas y asignar la responsabilidad correspondiente" o "la atribución de conductas ilícitas y la determinación de la responsabilidad correspondiente". 
del GBM y el FMI, en este apartado se analiza cómo se presentan ambas IFI en la actualidad en relación con el vínculo de sus mandatos respectivos y las cuestiones internacionales sobre derechos humanos. De este modo, se deja en claro que el análisis que hacen los apartados 3 y 4 de las obligaciones que surgen de los derechos humanos existentes y de la atribución de conductas que infrinjan esas normas no implica "imponer algo desde afuera" respecto de ellas, sino relacionarlas con debates ya existentes en ambas IFI.

\subsection{La posición oficial del GBM}

En recientes declaraciones relacionadas con sus políticas, el GBM subraya que los acontecimientos internos han demostrado "que se reconoce cada vez más la necesidad de que el Banco aborde la cuestión de los derechos humanos de una manera más explícita" y que "ha habido avances significativos en su reflexión sobre estos temas". ${ }^{5}$ Además, se señala expresamente que "existe una amplia superposición entre las áreas que se rigen por los tratados fundamentales sobre derechos humanos y aquellas en las que opera el Banco" ${ }^{\circ}$, al tiempo en que se reflexiona sobre "cómo seguir", se habla de "reconocer el rol de los derechos humanos en tanto principios legales que pueden informar una amplia gama de políticas y actividades del Banco". ${ }^{7}$ Incluso, de forma más directa, se habla de "comprender los derechos humanos como obligaciones legales exigibles". Esto se acerca a la terminología jurídica que se empleará en los apartados 3 y 4 del presente artículo, y se superpone con el

\footnotetext{
5 Ver (en inglés): http://web.worldbank.org/WBSITE/EXTERNAL/EXTSITETOOLS/0,,conten tMDK:20749693 pagePK:98400 piPK:98424 theSitePK:95474,00.html\#1. El sitio web hace referencia a publicaciones subyacentes, algunas de las cuales volverán a mencionarse en otras sescciones del presente artículo.

6 Ibidem

7 Ibidem

8 Ibidem
} 
inicio del razonamiento legal aquí desarrollado. En una declaración ya más puntual, desde el Banco se declara: "nuestros socios de la familia ONU más extendida tienen una ventaja comparativa en ese sentido. A diferencia del GBM, varios tienen mandatos que contemplan compromisos explícitos con los derechos humanos como, en algunos casos, capacidades de seguimiento y aplicación"9 (énfasis añadido por el autor). En otras palabras, el GBM parece de alguna manera "lamentarse" de que su mandato no haya sido explícitamente vinculado con los derechos humanos en el pasado, algo que en algún sentido le habría "simplificado" su labor actual (y tal sería la "ventaja comparativa") de algún modo.

$\mathrm{Al}$ formular su postura de esta manera, el Banco muestra su (no impugnada) apertura al terreno de los derechos humanos y hasta reconoce la utilidad práctica de que se lo relacione con normas en materia de derechos humanos y con mecanismos mediante los cuales se los hace valer. Sin embargo, debe agregarse que, a pesar de la terminología elegida, las referencias presentadas todavía están bastante "vacías" desde el punto de vista jurídico. En ese sentido, lo que reflejan es una mera declaración formal que luego deberá materializarse en hechos. Se puede decir lo mismo respecto del vínculo entre las palabras elegidas y la realidad. Esta última, de todas maneras, no es el aspecto central de este artículo. La forma en la que el GMB se presenta al mundo exterior se utilizará para confrontarlo más profundamente con sus obligaciones para con los derechos humanos y las consecuencias legales que eso conlleva.

\subsection{La posición oficial del FMI}

Varias cuestiones de las que se ocupa el FMI también se relacionan directamente con los derechos humanos. Sin embargo, se sabe muy bien que, en comparación con el GMB, el FMI es aún menos proclive a vincular tales actividades con

9 Ibidem 
las obligaciones que se desprenden del derecho de los derechos humanos. La cuestión de si esa postura es o no sostenible también se someterá a discusión en las páginas que siguen. Por ahora, el foco está sobre el vocabulario elegido por el propio FMI para ilustrar la superposición en términos de contenido entre su mandato y (el derecho de) los derechos humanos.

En un gran número publicaciones del FMI de la última década uno/a puede encontrar referencias a una variedad de derechos humanos. Tomaré un único ejemplo a modo de ilustración: un discurso de la directora gerente del FMI, Christine Lagarde, en una visita a Malawi a comienzos de 2013. En ocasión de analizar el "contexto económico global y regional" observa, entre otras cosas, que no debe "olvidar[se] la amenaza del precio de los alimentos y la escasez de comida. Hasta el momento, la presión al alza de los precios globales de los alimentos está concentrada en algunos cultivos como el maíz, el poroto de soja y el trigo. Pero las sequías y la pérdida de cosechas están convirtiéndose en peligros constantes en algunas áreas, lo cual trae graves consecuencias para el sustento económico e incluso para la vida de las personas". ${ }^{10}$ Otras observaciones de Lagarde en este discurso en particular se refieren a "mejorar el desarrollo humano" y ver el crecimiento económico como "el medio para alcanzar un fin superior: crear las condiciones para el florecimiento del potencial humano". En ese contexto, Lagarde cita al presidente de Malawi, Hastings Kamuzu Banda:

El crecimiento no es meramente el crecimiento del PBI. 'Crecimiento' implica riqueza y prosperidad para todos, oportunidades para todos, felicidad para todos, libertad política y económica para todos. 'Crecimiento' implica incrementar el número de madres que dan a luz de forma segura en los hospitales, y aumentar la

\footnotetext{
10 Christine Lagarde, Malawi - Economic Rebirth, Renewed Partnerships (discurso del 5 de enero de 2013), Lilongwe, Malawi. Disponible en inglés en: https://www.imf.org/en/ News/Articles/2015/09/28/04/53/sp010513
} 
cantidad de familias que tienen un plato de comida sobre la mesa. ${ }^{11}$

Las relaciones con los derechos humanos son muy evidentes, desde la libertad política hasta el derecho a la educación, desde el derecho a una salud adecuada hasta el derecho a la alimentación. Esta cita del discurso mencionado no quedaría fuera de lugar en un documento dedicado al objetivo social clave detrás del derecho de los derechos humanos: ¿cómo lograr una vida digna para todas las personas de todo el mundo y, especialmente en el contexto del presente artículo, para aquellas que viven en los Estados con los que el FMI mantiene una relación de trabajo? A su vez, debe mencionarse que el FMI no asume las consecuencias jurídicas de lo planteado en esta pregunta, y también debe observarse que incluso los discursos de la directora gerente del organismo pueden no necesariamente reflejar los puntos de vista preponderantes en la organización. De todas maneras, es razonable asumir que las citas al presidente de Malawi al menos reflejan un debate actual sobre la pertinencia directa y puntual de los derechos humanos dentro de la labor del FMI. Y como dijéramos para el GBM, el FMI tampoco puede permitirse el uso de palabras de este tenor de manera gratuita.

\section{Obligaciones aplicables relativas a los derechos humanos}

\subsection{Introducción}

Como sujetos de derecho internacional y también entidades con personería jurídica internacional, el GBM y el FMI tienen la capacidad de adquirir derechos y contraer obligaciones en virtud de sus instrumentos constitutivos, las reglas generales del derecho internacional y los tratados que han suscripto. Esto incluye obligaciones en el campo de los derechos humanos que se ejercen conjunta o separadamente con los Estados miembros. En este apartado se fundamentará con mayor profundidad esta

11 Ibidem 
"declaración de apertura" por medio de cinco puntos: un escrutinio adicional de los vínculos entre el mandato de las IFI y el derecho internacional de los derechos humanos (apartado 3.2); la incorporación de las IFI en el terreno del derecho internacional de los derechos humanos (apartado 3.3); la "prohibición política" (apartado 3.4); las obligaciones relativas a derechos humanos a cargo de los Estados cuando actúan en el contexto de las IFI (apartado 3.5) y las obligaciones que se desprenden de las relaciones (jurídicas) entre las IFI y los/as subcontratistas privados/as (apartado 3.6).

\subsection{Profundizando los vínculos entre el mandato de las IFI y el derecho internacional de los derechos humanos}

Como se demostró precedentemente, el GBM ha optado por no interpretar su mandato de manera separada de los acontecimientos que se producen en el ámbito de los derechos humanos, a la vez que por momentos se acerca a la terminología jurídica. Si bien el FMI también "juega” con la terminología sobre derechos humanos, lo hace de otra manera. La pregunta que surge ahora es qué obligaciones más específicas referentes a los derechos humanos pueden vincularse con los mandatos y con qué fundamentos. Antes de profundizar sobre estos aspectos, citaré las esclarecedoras palabras que Mac Darrow —quien fuera hace diez años autor de un libro fundamental sobre el tema- ${ }^{12}$ publicó en una entrada escrita en 2009 para la Enciclopedia de los Derechos Humanos: ${ }^{13}$

La Carta de las Naciones Unidas es probablemente la fuente más importante de deberes referentes a los derechos humanos para quienes integran la familia extendida de la ONU. La Carta de las Naciones Unidas

\footnotetext{
12 Mac Darrow, Between Light and Shadow; The World Bank, The International Monetary Fund and International Human Rights Law, (Hart Publishing, 2003).

13 Mac Darrow, "World and International Monetary Fund", en David Forsythe (jefe de redacción), Encyclopedia of Human Rights, (Oxford: Oxford University Press, 2009), Vol. 5, 373-381.
} 
obliga por igual al Banco y al FMI. Tanto el BIRF [Banco Internacional de Reconstrucción y Fomento] como la AIF [Asociación Internacional de Fomento] y el FMI han celebrado acuerdos formales de relación con la ONU. La promoción de los derechos humanos es un aspecto central de los propósitos del sistema de la ONU, conforme se establece en los Artículos 1 (3) y 55 de la Carta de las Naciones Unidas, aunque las obligaciones específicas no están bien definidas. Sin embargo, la Declaración Universal de Derechos Humanos (1948) y, hasta cierto punto, los tratados internacionales de derechos humanos que le siguieron, que gozan de amplia aceptación, son vistos por muchas personas como una exégesis o interpretación autorizada de las breves referencias a los derechos humanos que contiene la Carta de las Naciones Unidas. Si se consideran sus disposiciones pertinentes como un todo, es posible aseverar fehacientemente que la cooperación entre las IBW [Instituciones de Bretton Woods] y la ONU en los ámbitos económicos y sociales debería basarse, al menos en parte, en los principios de derechos humanos presentes en la Carta de la ONU. ${ }^{14}$

Estas aseveraciones se relacionan de por sí, más específicamente, con las ya expresadas sobre "los derechos humanos en sentido general”. En la misma obra, Mac Darrow agrega - lo que considero acertado- que "[1]a opinión jurídica internacional predominante indicaría que esto se traduce en la obligación mínima que el Banco y el FMI tienen de respetar (o al menos no incumplir) los compromisos vigentes relacionados con los derechos humanos en los países miembros y, posiblemente, además, de proteger los derechos humanos dentro del alcance de su competencia y sus actividades a nivel país". ${ }^{15}$ Además, según Mac Darrow, "[m]ás de un analista llega incluso a aseverar que estas instituciones deben promover o hasta velar por

\footnotetext{
14 Ibidem, 378.

15 Ibidem
} 
el cumplimiento de los derechos humanos". ${ }^{16}$ Dicho esto, Mac Darrow también hace referencia al tantas veces citado documento de 2006 Legal Opinion on Human Rights and the Work of the World Bank (Opinión legal sobre los derechos humanos y la labor del Banco Mundial, en adelante la Opinión Legal), elaborado por el Consejero Jurídico General del Banco en ese entonces, Roberto Dañino. ${ }^{17}$ Este documento, que fue redactado a solicitud de la gerencia ejecutiva del Banco, ${ }^{18}$ es considerado un "hito" por Darrow y tantos otros, y fue:

[...] marcado alejamiento de la doctrina conservadora de las décadas de los años ochenta y noventa [...] [que] postuló una interpretación deliberada y contextual del Convenio Constitutivo y dejó sentadas las bases de un marco propicio para que el Banco confrontara explícitamente las cuestiones de derechos humanos que surgían dentro de su amplio y complejo ámbito de operaciones, y para que apoyara a sus miembros en el cumplimiento de las obligaciones en materia de derechos humanos. Sorprendentemente, [']la Opinión [Legal'] concluía que el Convenio Constitutivo permite, y en algunos casos requiere, que el Banco reconozca la dimensión de los derechos humanos dentro de sus políticas y actividades de desarrollo, ya que ahora es evidente que los derechos humanos son una parte intrínseca de la misión del Banco. ${ }^{19}$

Si bien la Opinión Legal no fue presentada formalmente ante el directorio ejecutivo del Banco, según Darrow, su "efecto persuasivo [...] no depende de la aprobación del directorio; aunque para que sea formalmente vinculante respecto de las

\footnotetext{
16 Ibidem

17 Ver también Roberto Dañino, "The Legal Aspects of the World Bank's Work on Human Rights: Some Preliminary Thoughts", en Philip Alston y Mary Robinson (eds.), Human Rights and Development: Towards Mutual Reinforcement, (Oxford University Press, 2005), passim.

18 Ver Ana Palacio, The Way Forward; Human Rights and the World Bank, Instituto del Banco Mundial, Extensión Especial de Desarrollo de Informes Especiales, (Washington, 2006), 36.

19 Mac Darrow, op. cit. (2009 ff), 378.
} 
operaciones del banco, sus disposiciones clave tendrían que verse reflejadas en las políticas operativas del banco, las cuales sí requieren de dicha aprobación", y que la obtengan "no parece probable en el futuro inmediato". ${ }^{20}$ Sobre este último punto, es posible estar de acuerdo, aunque ello también depende del margen de tiempo que se tenga en mente. En lo personal, me expresaría a favor de la observación de Darrow en lo que respecta al presente y quizás al futuro cercano, pero puede que las cosas cambien y, de hecho, cambiarán. De todas maneras, es posible señalar que, se considere o no la Opinión Legal de 2006 un "hito", el documento muestra que hay cambios graduales dentro del Banco Mundial y que no todo es inalterable.

La consejera jurídica general que sucedió a Dañino, Ana Palacio, afirma que la Opinión Legal de 2006 evidencia una evolución clara de la interpretación jurídica restrictiva y preexistente que explícitamente tenía el Banco acerca de los derechos humanos; aunque ella la interpreta como una "acción permisiva - es decir, que permite pero no exige- de parte del Banco en relación con los derechos humanos". ${ }^{21}$ Desde ya que el uso de la palabra "permisiva" le da espacio también al FMI para actuar en concordancia con sus propios puntos de vista frente a cuestiones vinculadas con los derechos humanos y/o sus obligaciones legales. Ese "espacio" se cuestionará más adelante en el presente artículo con mayor detalle. La misma Palacio agrega que la Opinión Legal de 2006 clarifica "el estado del derecho" y "da al Banco la libertad de acción necesaria para explorar su propio rol en relación con los derechos humanos, dado que actualiza la postura legal adoptada internamente para ser congruente con las prácticas del Banco y del actual contexto jurídico internacional". ${ }^{22}$ Palacio también observa que está claro que los derechos humanos "pueden y a veces deben" ser un

\footnotetext{
20 Ibidem

21 Ana Palacio, op. cit., 36.

22 Ibidem
} 
factor, entre otros, que el Banco tenga en cuenta como parte de su proceso de toma de decisiones, a través del "reconocimiento del rol de los derechos humanos como principios legales [énfasis del original] que pueden informar una amplia gama de actividades y enriquecer la calidad y los fundamentos de las intervenciones vinculadas al desarrollo". ${ }^{23}$ Unos años más tarde, en un estudio publicado por el Banco Mundial y el Fondo de Fideicomiso Nórdico, Siobhán McInerney-Lankford y Hans-Otto Sano observaron que, a pesar de estos acontecimientos, el abordaje oficial del Banco Mundial respecto de los derechos humanos "sigue sin ser explícito en términos de la pertinencia directa o formal de sus deberes específicos o de sus obligaciones con arreglo a los tratados internacionales". ${ }^{24}$ Como se ha señalado, esta realidad aún se reflejaba en 2014 , lo cual demuestra que el GBM "juguetea” con la cuestión de las obligaciones legales dentro del ámbito de los derechos humanos.

En cuanto al FMI, es posible mencionar una serie de publicaciones, por ejemplo aquellas del ex Consejero General François Gianviti, entre otras, en que se reflexiona explícitamente sobre la "inexistencia de vínculos" entre el FMI y el derecho de los derechos humanos, más puntualmente el Pacto Internacional de Derechos Económicos, Sociales y Culturales (PIDESC). Según Gianviti:

Existen tres motivos para concluir que el Pacto no resulta aplicable al Fondo: el Fondo no es una de las partes del Pacto; las obligaciones impuestas por el Pacto obligan solo a Estados y no a organizaciones internacionales y, por último, el Pacto, en su Artículo 24, reconoce explícitamente que "[n]inguna disposición del presente Pacto deberá interpretarse en menoscabo de las disposiciones [...] de las constituciones de los organismos especializados que definen las atribuciones [...] de los organismos

\footnotetext{
23 Ibidem

24 Siobhán Mclnerney-Lankford y Hans-Otto Sano, Human Rights Indicators in Development, Washington: Banco Mundial y Fondo de Fideicomiso Nórdico, (2010), 6.
} 
especializados en cuanto a las materias a que se refiere el Pacto". 25

Asimismo, Gianviti analiza el argumento frecuentemente esgrimido respecto de que "las obligaciones establecidas en el Pacto son disposiciones imperativas del derecho internacional público general y, por lo tanto, vinculantes para todos los sujetos de derecho internacional, incluidos los organismos internacionales"; y que esto debería llevar a la conclusión "[de] que el Convenio Constitutivo del Fondo debe interpretarse en concordancia con el objetivo de promover los derechos contenidos en el Pacto, o bien considerar ser modificado, de ser necesario, para lograr estos objetivos". ${ }^{26}$ Gianviti concluye que una vez que se reconozca el principio "[de] que el Pacto prevalece sobre el Convenio [Constitutivo], es posible cuestionar toda la estructura legal e institucional dentro de la cual opera el Fondo". ${ }^{27}$ Claramente, el autor intenta escapar de la fuerza vinculante de las obligaciones internacionales en materia de derechos humanos.

Pero Gianviti toma distancia incluso de una visión más discreta de la vinculación entre el FMI y los derechos humanos, una en la que el FMI tiene que tener "en cuenta" - y frases similares- los derechos humanos, en particular el Pacto Internacional de Derechos Económicos, Sociales y Culturales. Uno de sus argumentos clave consiste en que el FMI no es un órgano de la ONU y no está sujeto a la normativa general de la ONU o al derecho internacional: el FMI es "una agencia intergubernamental, no una agencia de las Naciones Unidas". ${ }^{28}$ Gianviti observa que, de conformidad con el artículo 57 de la Carta de las Naciones

\footnotetext{
25 François Gianviti, Consejería General del FMI (1987-2004), Economic, Social and Cultural Rights and the International Monetary Fund, (2002), passim, esp. párrafos 6, 16 y 60. Disponible en inglés en: https://www.imf.org/external/np/leg/sem/2002/cdmfl/eng/gianv3.pdf

26 Ibidem párr. 14.

27 Ibidem

28 Ibidem párr. 16.
} 
Unidas, el FMI suscribió un acuerdo con la ONU por el cual esta última reconoce que "en virtud de la naturaleza de sus responsabilidades internacionales y de los términos de su Convenio Constitutivo, el FMI es una organización independiente y así se le requiere que funcione". ${ }^{29} \mathrm{Y}$ lo que es más importante: "el Artículo $\mathrm{X}$ del Convenio Constitutivo [...], si bien requiere del Fondo que coopere con 'cualquier organización internacional de carácter general' [es decir, las Naciones Unidas], especifica que '[1]os acuerdos para llevar a cabo tal cooperación que impliquen la modificación de cualquier disposición [del Convenio Constitutivo] solo podrán concertarse previa enmienda del mismo". ${ }^{30 " . ~ E s t a ~}$ línea de pensamiento lleva al autor a la conclusión de que entre el FMI y la ONU no hay una relación entre "agencias" sino de "soberanos iguales", ${ }^{31}$ cuestión que se analizará en el apartado 3.3.

Asimismo, con respecto al Convenio Constitutivo del FMI, Darrow observa que "[1]a capacidad o la obligación del FMI de considerar las cuestiones referentes a los derechos humanos vinculadas con su labor depende de cómo debería interpretarse su Convenio Constitutivo, aunque en menor medida que si se formulara la misma pregunta al Banco" y de cómo desea utilizar -y cómo usa realmente- sus "facultades implícitas". ${ }^{32}$ Por lo tanto, concluye Darrow, "quizás llame la atención que el Convenio [Constitutivo] del FMI resulta relativamente más permisivo en su alcance comparado con el del Banco y no contiene un equivalente de la prohibición política (...) que por tanto tiempo frustró las intenciones de insuflar vida a la carta de constitución del Banco ${ }^{33 "}$.

Por ahora, la pregunta clave es hasta qué punto se les puede "ordenar" al GBM y al FMI, sobre la base de los desarrollos en

$\begin{array}{ll}29 & \text { Ibidem } \\ 30 & \text { Ibidem } \\ 31 & \text { Ibidem } \\ 32 & \text { Darrow op. cit. (2009 ff), } 379 . \\ 33 & \text { Ibidem }\end{array}$ 
el ámbito de los derechos humanos y del derecho internacional general, que acepten obligaciones humanas directas y usen su posición para abordar cuestiones de derechos humanos como parte de su mandato.

\subsection{Incorporando las IFI al ámbito de la normativa internacional en materia de derechos humanos}

¿Está garantizado el espacio que el GBM y el FMI crean para sí mismos? Es posible discernir varios aspectos del derecho internacional de los derechos humanos y del derecho internacional general que se aplican directamente a ambas IFI. Se los mencionará de manera esquemática y no exhaustiva, con algunas pocas referencias.

En primer lugar, ambas IFI están sujetas necesariamente a las normas de derechos humanos que califican como normas imperativas de derecho internacional (ius cogens), tales como la obligación de abstenerse del genocidio, la tortura y la discriminación racial, así como la de respetar y proteger activamente el derecho a la autodeterminación de los pueblos.

En segundo lugar, las IFI están sujetas a los principios generales del derecho internacional (en materia de derechos humanos), como la obligación de reparación en el caso de un hecho internacionalmente ilícito y el principio de debida diligencia, tal como se lo entiende, al igual que a otros principios acuñados, en el contexto de los derechos humanos. ${ }^{34}$ Además, están sujetas a las normas de derecho internacional consuetudinario en materia de derechos humanos: las obligaciones que se desprenden de determinadas "convenciones sobre derechos

\footnotetext{
34 Véase, por ejemplo, la redacción que utiliza el Observatorio de Derechos Humanos (Human Rights Watch) en el artículo de julio de 2013 "Abuse-Free Development: How the World Bank Should Safeguard Against Human Rights Violations", donde se lee: "La debida diligencia continua debería incluir, identificar y analizar en todo momento los riesgos de derechos humanos en el trascurso de un proyecto y requerir que el Banco reconozca públicamente los riesgos relativos a los derechos humanos".
} 
humanos" de la OIT y que representan normas de derecho internacional consuetudinario tales como el C29, Convenio sobre trabajo forzoso (1930); el C87, Convenio sobre la libertad sindical y la protección del derecho de sindicación (1948); el C98, Convenio sobre el derecho de sindicación y de negociación colectiva (1949); el C100, Convenio sobre igualdad de remuneración (1951); el C105, Convenio sobre la abolición del trabajo forzoso (1957); el C111, Convenio sobre la discriminación (empleo y ocupación) (1958); el C138, Convenio sobre la edad mínima (1973) y el C182, Convenio sobre las peores formas de trabajo infantil (1999).

En tercer lugar, por tratarse de agencias especializadas de la ONU que han celebrado convenios de relación con el Consejo Económico y Social de la ONU de conformidad con los artículos 57 y 63 de la Carta de las Naciones Unidas, las dos instituciones tienen la obligación de respetar los principios y objetivos de la ONU, aunque el FMI en particular ha retenido, ocasionalmente, el derecho de que se lo considere también una entidad independiente de la ONU. ${ }^{35}$ Se puede estar de acuerdo con la Comisión de Derecho Internacional (CDI) que observa, en el contexto de sus estudios extensivos sobre la fragmentación del derecho internacional, que el término "régimen autónomo" (self-contained regime) —usado con frecuencia también para que las IFI justifiquen su posición especial— resulta "engañoso" y que "[n]ingún régimen jurídico está totalmente aislado del derecho internacional general". ${ }^{36}$

En cuarto lugar, existen numerosos pronunciamientos relevantes - tanto dentro de ciertos tratados como emanados de órganos particulares de supervisión en el ámbito de

\footnotetext{
35 Para una de las referencias más claras y explícitas al respecto, ver: François Gianvit, op. cit., especialmente los párrafos 6, 16 y 60.

36 Informe del Grupo de Estudio de la Comisión de Derechos Internacionales, finalizada por Martti Koskenniemi, "Fragmentation of International Law: Difficulties Arising from the Diversification and Expansion of International Law", documento de la ONU A/CN.4/L. 682, 13, abril de 2006, párrafo 193.
} 
los derechos humanos- que integran a las IFI en el ámbito jurídico del derecho internacional de los derechos humanos. Puntualmente, algunas Observaciones Generales realizadas por el Comité de Derechos Económicos, Sociales y Culturales (CESCR, por su sigla en inglés) proporcionan algunos ejemplos. En la Observación General del 2002 sobre el derecho al agua, por ejemplo, el CESCR señala que "[1]as instituciones financieras internacionales, especialmente el Fondo Monetario Internacional y el Banco Mundial, deberán tener en cuenta el derecho al agua en sus políticas de préstamo, acuerdos crediticios, programas de ajuste estructural y otros proyectos de desarrollo [...], de manera que se promueva el disfrute del derecho al agua". ${ }^{37}$ Con estas afirmaciones, el CESCR se refiere directamente a las IFI. En otras Observaciones Generales, se hace referencia a los Estados miembros de ambas IFI. En la Observación General del 2008 sobre seguridad social, por ejemplo, el CESCR señala: "[los] Estados Partes deben asegurar que sus acciones como miembros de las organizaciones internacionales tengan debidamente en cuenta el derecho a la seguridad social" y "[e]n consecuencia, los Estados Partes que sean miembros de instituciones financieras internacionales, como el Fondo Monetario Internacional, el Banco Mundial y los bancos regionales de desarrollo, deben adoptar medidas para que en sus políticas crediticias, acuerdos de crédito y otras medidas internacionales, se tenga en cuenta el derecho a la seguridad social". ${ }^{38}$ Las Observaciones Generales no son vinculantes en el caso de los Estados pero, para sintetizar un debate extenso y en línea con las afirmaciones de Conway Blake, convendremos que estas son "un testamento a la naturaleza dinámica del derecho internacional y sus instituciones" y que si bien su autoridad "no puede considerarse en los términos legales tradicionales", las Observaciones "emergen

37 Documento de la ONU E/C.12/GC/15 (2002), The Right to Water, párrafo 60.

38 Documento de la ONU E/C.12/GC/19 (2008), párrafo 58. 
como una interpretación autorizada que da lugar a un consenso normativo sobre el significado y alcance de determinados derechos humanos". 39

Un quinto aspecto se relaciona con el concepto del "derecho al desarrollo", como se establece, entre otros, en la Declaración sobre el Derecho al Desarrollo de $1986^{40}$. A pesar de quizás presentar un valor jurídico limitado ${ }^{41}$, la Declaración y también el concepto de desarrollo como tal pueden todavía resultar de utilidad como herramientas prácticas y semilegales (soft law o derecho blando) puntualmente para la defensa de los derechos humanos ${ }^{42}$. Además, en cuanto a la pertinencia del concepto del desarrollo para los mandatos del GBM y el FMI, no hay malentendido posible. Para mayor claridad sobre este punto se puede consultar, por ejemplo, la visión de las propias IFI sobre la necesidad de cooperar para dar cumplimiento a la Declaración del Milenio de 2000, que incluye los Ocho Objetivos de Desarrollo del Milenio, muchos de los cuales están directamente relacionados con los derechos humanos. ${ }^{43}$

39 Conway, Blake, "Normative Instruments in International Human Rights Law: Locating the General Comment", Centro de Derechos Humanos y Justicia Global, Documento de trabajo número 17, (Nueva York, 2008), 38.

40 Documento de la ONU A/RES/31/128, 4 de diciembre de 1976.

41 Ver: Arne Vandenbogaerde, "The Right to Development in International Human Rights Law: a Call for its Dissolution", Netherlands Quarterly of Human Rights, 2013, Vol. 31/2, 187-209.

42 En la misma línea, ver Olajuoke 0. Oduwole "International Law and the Right to Development: a Pragmatic Approach for Africa", conferencia inaugural en su cargo como profesora de la cátedra "Príncipe Claus" de Equidad y Desarrollo 2013/2015, brindada el 20 de mayo de 2014, en el Instituto Internacional de Estudios Sociales, La Haya, Países Bajos, 3.

43 Ver el documento reciente: The IMF and the Millennium Development Goals, ficha técnica del FMI, 2014. Disponible en inglés en: https://www.imf.org/external/np/exr/facts/pdf/mdg. pdf. También pueden consultarse los sucesivos informes anuales de seguimiento mundial del Banco Mundial y del FMI, hasta el momento del presente artículo (2004-2013), Washington, D.C.: Banco Mundial, y Banco Mundial y OCDE. Ver también: OCDE y Banco Mundial, Integrating Human Rights into Development: Donor Approaches, Experiences, and Challenges, (2013, 2da. Edición), Washington D.C., EE. UU. 


\subsection{La "prohibición política"}

Al entrar en el análisis de las múltiples relaciones entre los mandatos de las IFI y los derechos humanos también se aborda el terreno de la llamada "prohibición política", aspecto al que recurre el GBM. El artículo IV, sección 10 del Convenio Constitutivo del Banco Mundial dispone lo siguiente: "[e]l Banco y sus funcionarios no podrán intervenir en asuntos políticos de ningún miembro ni tampoco permitirán que la clase de gobierno de un miembro o de miembros interesados sea factor que influya en sus decisiones"; y también: "[t]odas sus decisiones se inspirarán únicamente en consideraciones económicas". ${ }^{44}$ Esta "prohibición política" tiene que ver con la visión de quienes fundaron el Banco de que fuera una institución imparcial y neutra. El Convenio Constitutivo original impedía explícitamente al Banco tratar cualquier asunto de carácter político y, según este, los derechos humanos eran de esa naturaleza.

La "prohibición política" original reflejaba el pensamiento predominante sobre la soberanía y los derechos humanos luego de la Segunda Guerra Mundial, mientras que en la década de los años sesenta, "desde el Banco se entendían las cuestiones sobre los derechos humanos en el contexto de si se debía o no tratar con regímenes con antecedentes negativos en materia de derechos humanos, o con aquellos de los que se supiera acerca de sus violaciones a tales derechos, por lo general civiles y políticos". ${ }^{45}$ En aquel momento, el Banco también utilizó su Convenio "para rechazar las críticas que recibía al involucrarse con este tipo de regímenes al clasificar las preocupaciones por los derechos humanos como "políticas"”. ${ }^{46}$ Sin embargo, como se

\footnotetext{
44 Convenio Constitutivo, Banco Internacional de Reconstrucción y Fomento, (1944), elaborado en la Conferencia Monetaria y Financiera de las Naciones Unidas, Bretton Woods, New Hampshire, Estados Unidos. Sanae Fujita, "The Challenges of Mainstreaming Human Rights in the World Bank", 3 The International Journal of Human Rights, 2011, Vol. 15, 376.

45 Sanae Fujita, "The Challenges of Mainstreaming Human Rights in the World Bank", 3 The International Journal of Human Rights, 2011, Vol. 15, 376.
}

46 Ibidem 
vio anteriormente, hay vientos de cambio, y ambas IFI oponen menos resistencia, de distintas maneras y en grado diferente, a analizar "preocupaciones no económicas". En relación con esta frase, coincidimos con Adam McBeth en que "la distinción entre los asuntos económicos y no económicos es artificial y por lo general poco defendible, en particular si se colocan a los derechos humanos en la segunda categoría, que está, además, prohibida". ${ }^{47}$ El término "prohibido" se relaciona con la idea de "asuntos internos de los Estados soberanos". Sin embargo, es bien sabido que en la actualidad existe un campo extenso del ámbito de los derechos humanos que ya no pertenece a los asuntos internos de los Estados. Entre los primeros demarcadores de esos acontecimientos, podemos mencionar el fallo de 1970 de la Corte Internacional de Justicia en el caso Barcelona Traction, con su famoso dictamen sobre obligaciones erga omnes (obligaciones que "conciernen a todos los Estados") ${ }^{48}$ y el documento Declaración y Programa de Acción de Viena de 1993 (que establece: "la promoción y protección de todos los derechos humanos es una preocupación legítima de la comunidad internacional"). ${ }^{49}$ También cimentados en nociones como estas, otros debates extensos derivaron en resultados equivalentes, como el del artículo 48 del Proyecto de artículos sobre la responsabilidad del Estado por hechos internacionalmente ilícitos —el artículo 48 (1) (b), que se relaciona con el incumplimiento de obligaciones "con relación a la comunidad internacional en su conjunto"-, y el de la Responsabilidad de Proteger, concepto inspirado y basado en la transición de una "soberanía como control" a una "soberanía como

\footnotetext{
47 Adam McBeth, "A Right by an Other Name: The Evasive Engagement of International Financial Institutions with Human Rights", The George Washington International Law Review, 2009, Vol. 40, p. 1110.

48 Ver sitio web disponible en inglés y francés en: http://www.icj-cij.org/docket/index.php ?p1=3\&p2=3\&k=1a\&case=50\&code=bt2\&p3=4, párrafos 33 (y 34).

49 Adoptados por la Conferencia Mundial de Derechos Humanos, Viena, 1993. Disponible en inglés en: http://www.ohchr.org/EN/Professionallnterest/Pages/Vienna.aspx, párrafo I, 4.
} 
responsabilidad", que también se construye a partir de estas nociones. ${ }^{50}$ En línea con estos pronunciamientos y documentos, y con lo que ellos reflejan, está desarrollándose una tendencia global que reclama otra visión de la soberanía, que es el concepto básico detrás de la "prohibición política". Claramente, la tendencia está alejándose de un enfoque bastante exclusivo de la soberanía de los Estados (que responde a la idea de que cada Estado "se ocupe de sus propios asuntos") y acercándose a uno que eleva la dignidad humana de fondo por encima de ciertas formas y ciertos derechos soberanos anteriormente concebidos. No es necesario ser partidario de los/as autores/as que sostienen que la terminología referida a los derechos humanos y sus objetivos deben permear, y de hecho ya lo hacen, hacia (casi) todos los demás ámbitos de la política y del derecho internacionales para poder ver la relevancia y la ocurrencia concreta de la terminología de derechos humanos en otros terrenos del orden jurídico internacional. En un artículo reciente en el que Vassilis Tzevelekos, en líneas generales, criticaba en extremo las supuestas dimensiones reales de la "humanización del orden jurídico internacional", el autor llega a la conclusión - luego de desmontar uno por uno los altisonantes aspectos de lege ferenda de la tendencia a la humanización- de que las obligaciones erga omnes (partes) y el principio de debida diligencia son dos herramientas "sistémicas" fundamentales para la humanización del derecho internacional. Y también, según Tzevelekos:

[...] ambas herramientas forman parte del derecho positivo moderno, pero pueden también contribuir favorablemente con una humanización más profunda del derecho internacional. Esto ocurre porque tienen el potencial, entre otras cosas, de limitar la voluntad del Estado, establecer una jerarquía normativa material ocasional consistente en otorgar prioridad condicional a la observancia de los derechos humanos, aportar un tono

50 Comisión Internacional sobre la Intervención y la Soberanía Estatal, The Responsibility to Protect, Report of the International Comission, 2001, Ottawa: IDRC, párrafo 2, 14. 
comunitario al derecho internacional e invitar a los Estados a ser proactivos en la protección colectiva de sus intereses y valores comunes ${ }^{51}$.

Son palabras elocuentes a la hora describir el estado del arte sobre la tendencia a la humanización. Más aún, Tzevelekos concluye que el proceso de humanización del derecho internacional necesita equilibrarse respecto de los orígenes descentralizados y soberanistas del sistema pluralista de derecho internacional. En lo personal, también deseo expresarme a favor de esto y agregar que la referencia a la soberanía y sus límites es, en mi opinión, clave.

Al llevar este análisis a las IFI y una vez más responder a la interpretación de Gianviti del Convenio Constitutivo del FMI, con su frase concluyente sobre los "soberanos iguales", puede argumentarse con fundamento sólido que los respectivos Convenios Constitutivos de ambas IFI deben considerarse instrumentos vivos y dinámicos, que deben interpretarse a la luz de los acontecimientos legales hasta el presente (de lege lata) y las tendencias actuales (una mezcla de de lege lata y de lege ferenda). Lo segundo reviste el cambio de paradigma desde el concepto de una soberanía que mira introspectivamente cómo proteger sus intereses nacionales, hacia una soberanía como responsabilidad conjunta por lo que sucede en el mundo exterior, donde los problemas ya no son "intraterritoriales". A la luz de las ideas precedentes y de las actuales miradas extraterritoriales sobre los derechos humanos, queda claro que ya no es sostenible la conceptualización original de la "prohibición política". Además de la ya citada declaración de la CDI que indica que "[n]ingún régimen jurídico está totalmente aislado del derecho internacional general", en otra observación desde la misma Comisión se señala:

51 Vassilis Tzevelekos, "Revisiting the Humanisation of International Law: Limits and Potential - Obligations Erga Omnes, Hierarchy of Rules and the Principle of Due Diligence as the Basis for Further Humanisation", 1 Erasmus Law Review, 2013, Vol. 6, passim. La cita ha sido tomada del abstract del artículo. 
[...] es difícil concebir de qué manera los creadores del régimen pudieron haber convenido en no incorporar esos principios generales (es decir, prescindir de ellos). El debate sobre la nueva competencia de los Estados de elegir las partes del derecho consuetudinario que deseen aplicar terminó después de la descolonización, sin que hubiera habido mucho "rechazo" de la vieja costumbre. Son pocos los que querrían establecer relaciones con un régimen especial que afirma rechazar en su totalidad todo el derecho internacional general. En tal caso, ¿por qué querría alguien (incluso quienes lo establecieron) considerar seriamente al régimen? ${ }^{52}$

Así, la CDI llama a los Estados y, literalmente y por implicancia directa, a sus organizaciones internacionales, a alejarse de abordajes minimalistas de los sucesos vinculados al derecho internacional. Aunque se trate de un llamamiento de lege ferenda, los argumentos de fondo que lo sostienen dentro del ámbito del derecho internacional de los derechos humanos no pueden considerarse insignificantes, aun si así lo desearan ambas IFI.

\subsection{Las obligaciones en materia de derechos humanos de los Estados que actúan en el contexto de las IFI}

Las IFI, por su naturaleza, tienen un accionar transnacional y sus Estados miembros, mientras actúen dentro del marco de las IFI, afectarán concretamente el goce de los derechos humanos en los Estados prestatarios, ya sea de forma positiva o negativa $\mathrm{y}$, por lo tanto, tienen un accionar extraterritorial. A lo ya dicho previamente sobre (las Observaciones Generales de) el CESCR y las obligaciones de los Estados Partes del PIDESC en su accionar dentro del marco del GBM y el FMI, podemos agregar que las obligaciones extraterritoriales en materia de derechos humanos de los Estados miembros de las organizaciones internacionales han sido el centro de atención, por ejemplo, en los Principios

52 Informe del Grupo de Estudio de la Comisión de Derecho Internacional finalizado por Martti Koskenniemi, op. cit., párr. 185. 
de Maastricht sobre las Obligaciones Extraterritoriales de los Estados en el Área de los Derechos Económicos, Sociales y Culturales del año 2011 (Principios de Maastricht sobre las ETO, por su sigla en inglés). ${ }^{53}$ Según ellos, dichas obligaciones implican una prohibición de intervención directa o indirecta, es decir, de toda conducta que "menoscabe la capacidad de otro Estado u organización internacional de cumplir con sus propias obligaciones en materia de derechos económicos, sociales y culturales" (Principio 21) o que "ayude, asista, dirija, controle o ejerza coerción sobre otro Estado u organización internacional para que este viole sus propias obligaciones en materia de derechos económicos, sociales y culturales, en caso de que aquellos Estados lo hagan con conocimiento de las circunstancias del hecho" (ibídem). En cuanto a la frase "con conocimiento...", a la luz del derecho internacional general, puede agregarse que la ignorancia no es siempre legítima defensa. (Este aspecto y otros relacionados se desarrollan en profundidad en el apartado 4.2). Asimismo, en los Principios de Maastricht sobre las Obligaciones Extraterritoriales se confirman de diversas maneras las obligaciones de los Estados de observar los derechos humanos. Por ejemplo, el Principio 29 requiere que los Estados adopten medidas "a fin de crear un entorno internacional propicio para el cumplimiento universal de los derechos económicos, sociales y culturales, también en cuestiones relativas al comercio bilateral y multilateral, inversión, tributación, finanzas, protección medioambiental y cooperación para el desarrollo".

También es pertinente nombrar los Principios Rectores de las Naciones Unidas (UNGP, por su sigla en inglés) sobre las Empresas y los Derechos Humanos, en especial el Principio 10:

\footnotetext{
53 "Principios de Maastricht sobre las Obligaciones Extraterritoriales de los Estados en el Área de los Derechos Económicos, Sociales y Culturales", (2011), disponible en inglés en: http://www.etoconsortium.org/en/library/maastricht-principles. Para un análisis pormenorizado, ver Ashfaq Khalfan e lan Seiderman, “Extraterritorial Human Rights Obligations: Wider Implications of the Maastricht Principles and the Continuing Accountability Challenge", en Wouter Vandenhole (ed.), Challenging Territoriality in Human Rights Law. Building Blocks for a Plural and Diverse Duty-Bearer Regime, (Routledge, 2015), cap. 2.
} 
Los Estados cuando actúen en calidad de miembros de instituciones multilaterales que tratan cuestiones relacionadas con las empresas, deberán:

(a) tratar de asegurarse de que esas instituciones no limiten la capacidad de los Estados miembros de cumplir su deber de protección ni pongan trabas a la observancia de los derechos humanos por las empresas;

(b) alentar a esas instituciones, en el marco de sus respectivos mandatos y capacidades, a promover el respeto de los derechos humanos entre las empresas y a ayudar a los Estados que lo soliciten a cumplir su deber de protección contra las violaciones de los derechos humanos cometidas por empresas, en particular mediante iniciativas de asistencia técnica, fomento de la capacidad y sensibilización;

(c) inspirarse en estos Principios Rectores para promover el mutuo entendimiento y la cooperación internacional en la gestión de problemas relacionados con las empresas y los derechos humanos. ${ }^{54}$

Si bien es posible argumentar que los UNGP pueden no ser igualmente aplicables a todas las entidades del GBM, en cualquier caso, cubrirían a la Corporación Financiera Internacional, la cual opera (y otorga financiamiento) junto con el sector privado. Asimismo, hay también temas que se desprenden del mandato del FMI en términos de sus acuerdos de giro o política de condicionalidad y/o los programas de ayuda que requieren de interacción con corporaciones y empresas de otra naturaleza en los países miembros prestatarios (en el apartado 3.6 se profundiza sobre la relación entre ambas IFI y el sector privado).

Además, debe observarse que cuando se considera la participación de los Estados dentro de las IFI, los/as directores/as ejecutivos/as de estas actúan como sus respectivos representantes, pero también hacen lo propio respecto de los Estados

54 Principios Rectores Sobre las Empresas y los Derechos Humanos, ACNUDH, Ginebra, 2011. 
miembros que los/as designaron. No obstante, en el contexto actual, sería demasiado proponerse un análisis exhaustivo de todas las posibles consecuencias de estos actos en una doble capacidad. ${ }^{55}$ Algunos Estados miembros de las IFI ya han adoptado legislación nacional en materia de derechos humanos que impone ciertos deberes sobre los directores/as ejecutivos/as que los representan. En los Estados Unidos, un Título del Compendio de Normas Federales de los Estados Unidos titulado "Derechos humanos y políticas de asistencia de los Estados Unidos con instituciones financieras internacionales" estipula que "el gobierno de los Estados Unidos, con su voz y voto en el Banco Internacional de Reconstrucción y Fomento, la Asociación Internacional de Fomento, la Corporación Financiera Internacional [...] y el Fondo Monetario Internacional [...] promoverá la causa de los derechos humanos [...]"56 (énfasis añadido). Y “[...] el Secretario del Tesoro instruirá al directorio ejecutivo de cada una de las instituciones mencionadas que al desempeñar sus deberes considere: (1) acciones específicas por parte del poder ejecutivo o del congreso en su totalidad sobre programas individuales de asistencia bilateral por cuestiones de derechos humanos: (2) en qué medida la asistencia económica provista por las instituciones mencionadas beneficia directamente a los más necesitados en el país destinatario". ${ }^{57}$ La ley recuerda explícitamente a los/as directores/as ejecutivos/as estadounidenses que tomen en cuenta los derechos humanos al momento de tomar decisiones en el contexto de las IFI, y que

\footnotetext{
55 Para un estudio pormenorizado, ver: Ana Sofía Barros y Cedric Ryngaert, “The Position of Member States in (Autonomous) Institutional Decision-Making: Implications for the Establishment of Responsibility", International Organizations Law Review, 2014, Vol. 11, pp. 1 ss.

56 Título 22 del Compendio de Normas Federales de los Estados Unidos, artículo 262d, Derechos humanos y las políticas de asistencia de los Estados Unidos con las instituciones financieras internacionales (Human Rights and United States Assistance Policies with International Financial Institutions), sección sobre objetivos de políticas (Policy Goals).

57 Ibidem, sección sobre Consideraciones de las políticas para el directorio ejecutivo de instituciones en la implementación de deberes (Policy Considerations for Executive Directors of Institutions in Implementation of Duties).
} 
contemplen la opción de no tomar decisiones si el programa no busca brindar acceso a las necesidades básicas de las personas y resolverlas, es decir, si no vela por la observancia de derechos humanos tales como el derecho a la alimentación, a la atención médica adecuada y a la vivienda de las personas que habitan en los Estados prestatarios. Desde un punto de vista estrictamente legal, no se necesitarían leyes como estas porque los Estados y sus representantes tendrían, de todas formas, la obligación de actuar en cumplimiento de los derechos humanos al momento de tomar acciones que tienen efectos externos sobre los derechos humanos ${ }^{58}$; por otro lado, sin embargo, no está de más destacar estas obligaciones de manera más específica. La pregunta clave entonces es si "la causa de los derechos humanos" y "el acceso a las necesidades básicas de las personas" se entenderán o no en consonancia con el derecho internacional de los materia derechos humanos. De ser así, tendría sentido que otros Estados miembros de las IFI siguieran el ejemplo de los Estados Unidos.

\subsection{Las obligaciones que se desprenden de las relaciones (jurídicas) entre las IFI y los subcontratistas privados}

Para concluir este apartado sobre obligaciones relativas a los derechos humanos, debemos hacer algunos comentarios sobre las relaciones entre las IFI y los subcontratistas privados. Sin entrar en un análisis de las obligaciones directas de las propias empresas en materia de derechos humanos, es posible distinguir dos relaciones diferentes entre una IFI y sus subcontratistas privados. La primera hace referencia a un vínculo directo, por ejemplo, el de los/as empleados/as de seguridad que trabajan para una IFI pero son legalmente contratados/as

\footnotetext{
58 Ver Fons Coomans y Menno T. Kamminga (eds.), Extraterritorial Application of Human Rights Treaties, 2004, Intersentia. Y ver la publicación reciente: Malcolm Langford, Wouter Vandenhole, Martin Scheinin y Willem van Genugten (eds.), Global Justice, State Duties. The Extraterritorial Scope of Economic, Social and Cultural Rights in International Law, (Cambridge University Press, 2013).
} 
por una empresa de seguridad privada. Una relación indirecta surge cuando una IFI apoya la colaboración entre un Estado y un subcontratista privado, por ejemplo dentro del contexto de una alianza público-privada.

Cuando se infringen estándares de derechos humanos en una relación directa, la IFI debe actuar con muchísimo cuidado al seleccionar al subcontratista, por ejemplo, mediante una verificación exhaustiva de su desempeño anterior y la redacción de contratos que contemplen disposiciones adecuadas para el caso de que el subcontratista infrinja normas del ámbito de los derechos humanos. En un caso así, la IFI tendría al menos la obligación conjunta de encontrar soluciones adecuadas, cualquiera sea su forma (indemnización, reparación, cumplimiento), si el contratista privado incurriera en violaciones a los derechos humanos. Las obligaciones de derechos humanos y las consecuencias de no cumplir con ellas no pueden "anularse mediante un contrato" y, en definitiva, el interés de las víctimas del incumplimiento de estas obligaciones no debe desestimarse, por ejemplo, en el caso de un subcontratista privado que se declara en quiebra o cambia su estatus legal después (o durante) la vigencia del contrato. ${ }^{59}$

En abril de 2010 los presidentes de los más importantes bancos multilaterales de desarrollo (BMD) firmaron un acuerdo para la inhabilitación conjunta de empresas e individuos involucrados en ilícitos en el marco de proyectos de desarrollo financiados por los BMD. ${ }^{60}$ De conformidad con el acuerdo, las entidades inhabilitadas por un BMD pueden ser sancionadas por

\footnotetext{
59 Para una profundización sobre estas obligaciones y otros temas relacionados sobre las responsabilidades (estatales), ver Willem van Genugten, Nicola Jägers y Evgeni Moyakine, "Private Military and Security Companies, Transnational Private Regulation and Public International Law: From the Public to the Private and Back Again?", en Jernej Letnar Černič y Tara Van Ho (eds.), Human Rights and Business: Direct Corporate Accountability for Human Rights, (Wolf Legal Publishers, 2015), 387-406.

60 "Agreement for Mutual Enforcement of Debarment Decisions' (2010). Disponible en inglés en: http://go.worldbank.org/B699B73000
} 
la misma conducta impropia en otros contextos de trabajo con otros bancos de desarrollo participantes. El objetivo es utilizar una lista de compañías inhabilitadas (o "lista negra") para cerrar un vacío legal que ha permitido que una compañía anteriormente inhabilitada por un BMD continuara obteniendo contratos financiados por otros BMD. Aunque esta iniciativa lucha principalmente contra el fraude y la corrupción, el alcance del sistema puede ampliarse para incluir también violaciones a los derechos humanos.

En el caso de vulneraciones de derechos humanos en relaciones indirectas, será más difícil establecer las obligaciones exactas de una IFI, pero no imposible. En ese sentido, es importante establecer hasta qué punto la IFI tiene control sobre el subcontratista contratado por el Estado prestatario. En la medida en que la IFI influya sobre la decisión de qué actor privado se debe convocar, esta tendrá la obligación de actuar como se describió en el contexto de la relación directa. En cualquier caso, y sea cual fuere la forma en que tome la decisión de emplear al subcontratista, se requerirá una y otra vez un análisis pormenorizado de la relación de control fáctica entre la IFI, el Estado miembro y la compañía privada. De todas maneras, se trataría de una cuestión de atribución de la conducta y no de una obligación (relativa a los derechos humanos) propiamente dicha.

\section{La atribución de conductas ilícitas a las IFI y a sus Estados miembros}

Por un lado, está el hecho de estar sujeto a obligaciones relativas a derechos humanos. Por el otro, está la determinación de la responsabilidad exacta frente al incumplimiento de esas obligaciones por parte de las IFI como coobligadas en el ámbito del derecho internacional de los derechos humanos, lo cual lógicamente será el siguiente punto a ser analizado. En este apartado se analizan tres cuestiones: la atribución de la conducta ilícita y la determinación de la correspondiente responsabilidad de la IFI (apartado 4.1), el significado de tener 
"control" (apartado 4.2) y la cuestión de las responsabilidades principales, subsidiarias y compartidas (apartado 4.3).

\subsection{La atribución de conductas ilícitas y la determinación de responsabilidad}

Las circunstancias por las cuales las Organizaciones Internacionales (OI) pueden ser responsabilizadas por hechos internacionalmente ilícitos han sido establecidas en el Proyecto de Artículos sobre la Responsabilidad de las Organizaciones Internacionales (PAROI) de la Comisión de Derecho Internacional (CDI). ${ }^{61}$ Las reglas del PAROI se utilizan aquí como una de las lentes posibles a través de la cual se puede observar la responsabilidad (conjunta) de las IFI respecto del incumplimiento de las obligaciones referentes a los derechos humanos. En virtud del artículo 4 del PAROI, se requieren dos condiciones conforme el derecho internacional para determinar la responsabilidad de las IFI: 1) que se haya incumplido alguna de sus obligaciones internacionales, 2) que el incumplimiento en cuestión sea atribuible a ellas. Respecto de la última condición, la mayoría de las veces la conducta que se atribuye será la oficial de los órganos y agentes de las IFI que actúen dentro del marco general de sus funciones, aunque esta exceda la competencia del órgano o agente o contravenga a sus instrucciones (cf. artículo 2 (c) y artículo 8 del PAROI).

Los actos y las omisiones de las IFI pueden dar lugar a violaciones de los derechos humanos al prestar ayuda o asistencia (artículo 14), o dirigir o controlar (artículo 15) a un Estado (u otra OI) en la comisión de un acto ilícito. Los Comentarios de la CDI al Proyecto de Artículos, ${ }^{62}$ además ponen el énfasis en dos condiciones: la competencia de la OI y la intención del Estado

\footnotetext{
61 Aprobado por la Comisión de Derecho Internacional en su $63^{\circ}$ período de sesiones, en 2011, y presentado a la Asamblea General como parte del informe de la Comisión sobre la labor de ese período de sesiones (A/66/10, párr. 87). Véase: Documento de la ONU A/RES/ 66/100, 27 de febrero de 2012, texto y anexo.

62 Disponible en inglés en: http://legal.un.org/ilc/texts/instruments/english/commentaries/ 9_11_2011.pdf
} 
miembro. El artículo 61 del PAROI establece que, para poder responsabilizarla, la organización deberá tener competencia en relación con el objeto de la obligación internacional del Estado en cuestión. El Comentario al artículo deja en claro que estas situaciones no se limitan solo a la transferencia de funciones de un Estado a una organización:

Lo que es pertinente a la responsabilidad internacional en virtud del presente artículo es que la obligación internacional corresponda a la esfera en que se atribuye competencia a la organización internacional. La obligación puede referirse específicamente a esa esfera o ser de un carácter más general, como las obligaciones contraídas en virtud de tratados para la protección de los derechos humanos. ${ }^{63}$

De este modo, es claro que las reglas del PAROI abordan obligaciones en relación con las OI en sí y la responsabilidad que puede invocarse si estas no cumplen con sus obligaciones. En cuanto a la intención de los Estados miembros que actúan en el contexto de las OI, se establece que:

[u]n Estado miembro de una organización internacional incurre en responsabilidad internacional si trata de eludir el cumplimiento de una de sus obligaciones internacionales prevaliéndose de que la organización es competente en relación con el objeto de dicha obligación, induciendo a la organización a cometer un hecho que, de haber sido cometido por el Estado, habría constituido una violación de la obligación (artículo 61 del PAROI).

En el caso de los Estados miembros que actúan en el contexto de las IFI, la atribución de la conducta impropia se relaciona con las propias obligaciones que tienen como Estados soberanos, ya sea porque son partes de un convenio cuyo contenido está en juego en una decisión concreta de una IFI, o porque la norma pertinente es de naturaleza consuetudinaria.

63 Observaciones al artículo 60 del PAROI, párrafo 6 (en su versión en inglés). 
Básicamente, no hay diferencia si actúan por sí solos o en el contexto de una IFI. En cuanto a la atribución de conductas que infringen esas normas, la regla básica indica que si tienen el "control" deben aceptar la responsabilidad correspondiente. Lo mismo aplica, mutatis mutandis, a las propias IFI.

Aunque resulte pertinente, en el presente contexto sería ir demasiado lejos analizar en detalle las responsabilidades específicas de cada uno de los dos actores en relación con cada uno de los elementos de la tipología tripartita sobre derechos humanos (respetar, proteger y cumplir). ${ }^{64}$ En lugar de ello, se decide concentrarse en dos cuestiones: en primer lugar, qué significa exactamente que un Estado o una IFI tenga el "control" y, en segundo lugar, cómo se distribuye la responsabilidad entre las IFI y los Estados miembros.

\subsection{Tener "control"}

En el apartado 3.3 de este artículo se mencionaron dos de las Observaciones Generales del CESCR que resultan pertinentes en el contexto actual y que "recuerdan" a los Estados lo que tienen que hacer cuando actúan en contextos de OI como el GBM y el FMI. Al tiempo que especifica esa conducta, en más de una ocasión el CESCR también ha hecho referencia al alcance del "comportamiento deseado". ¿Qué puede solicitarse de forma realista a los Estados Parte del PIDESC cuando están activos en el contexto de las OI, más específicamente de IFI? En algunas de sus Observaciones Finales, por ejemplo en reacción al informe periódico de Estado de Alemania del 2001, el CESCR alentó "al Estado parte, como miembro de las instituciones financieras internacionales, en particular el FMI y el Banco Mundial, a bacer todo lo que pueda para asegurar que las políticas y decisiones de esas organizaciones estén en conformidad con la obligaciones de los Estados Partes del Pacto"

64 Para un análisis exhaustivo, ver: Ashfaq Khalfan e lan Seiderman, op. cit. 
(énfasis añadido). ${ }^{65}$ Aquí considero que se trata de una formulación interesante aunque al mismo tiempo bastante imprecisa, y que está lejos de orientarse a resultados o vincularse a un lenguaje duro en materia de deberes. Aun así, coincido con la visión de Magdalena Sepúlveda en cuanto a que estas palabras también pueden interpretarse como una llamada a los Estados a llevar adelante "un rol activo orientado a la implementación del Pacto" ${ }^{66}$ Pero, ¿qué significa "activo"? Según Ashfaq Khalfan, "[r]equerir que un Estado 'haga todo lo que pueda' para garantizar que las organizaciones internacionales actúen conforme al PIDESC necesita implícitamente que los Estados tengan la obligación de respetar, proteger y cumplir los derechos ESC en el contexto de su participación dentro de estas organizaciones". ${ }^{67}$ Aunque Khalfan hace literalmente una lectura entre líneas de los hallazgos del CESCR, considero que arriba a una conclusión correcta en cuanto a la intención del Comité y, a su vez, que hace que esa intención resulte más específica que la redacción elegida por el propio Comité. Pero a menos que pensemos que las obligaciones de respetar, proteger y cumplir los derechos humanos son totalmente claras en todas y cada una de las situaciones (y sabemos que ello no sucede a pesar de la cantidad de instrumentos legales y semilegales disponibles y la abundante jurisprudencia), es necesario ir un paso más allá. En un intento de aportar mayor claridad a estas cuestiones, los Principios de Maastricht sobre las OET mencionan la obligación de evitar causar daño:

Los Estados deben abstenerse de actos u omisiones que creen un riesgo real de anular o menoscabar el disfrute de los derechos económicos, sociales y culturales extraterritorialmente. La responsabilidad de los Estados se

\footnotetext{
65 Ejemplo tomado de Langford, Coomans y Gómez Isa, op. cit., 104.

66 Ibidem

67 Ashfaq Khalfan, "Division of Responsibility amongst States", en Malcolm Langford, Wouter Vandenhole, Martin Scheinin y Willem van Genugten (eds.), op. cit., 311.
} 
activa cuando tal anulación o menoscabo es un resultado previsible de su conducta. La incertidumbre sobre los posibles impactos no justifica tal conducta. (Principio 13, énfasis añadido).

Considero que se trata de una buena guía, en líneas generales, aunque aplicarla en su totalidad en el contexto de las IFI parece una meta casi imposible de alcanzar. En los párrafos siguientes se analizará este punto con más detalle.

Antes de volver específicamente al tema de la responsabilidad de las IFI, es conveniente dar una mirada a los esfuerzos y los resultados obtenidos en torno al establecimiento de estándares en cuanto a qué es tener "control". Además del CESCR, otros tantos órganos de supervisión de los derechos humanos así como, por ejemplo, la Corte Internacional de Justicia y varios Tribunales Penales Internacionales e investigadores/as que reflexionan sobre la jurisprudencia de esta índole han elaborado estándares como el "control efectivo", el "control general", la "influencia decisiva", la "debida diligencia", las "obligaciones positivas" y la "proximidad"; y si analizamos más el resultado que las contribuciones, por ejemplo, la "protección equivalente", la "doctrina de la conducta" y la "doctrina de los efectos". ${ }^{68}$ Lo que se busca incesantemente es acuñar un nombre adecuado para el alcance de las obligaciones relativas a los derechos humanos de cualquier actor/a y el establecimiento de la responsabilidad correspondiente por las violaciones de

\footnotetext{
68 Para mayor detalle consultar, entre otras fuentes: Smita Narula, "International Financial Institutions, Transnational Corporations and Duties of States", en: Malcolm Langford, Wouter Vandenhole, Martin Scheinin y Willem van Genugten (eds.), op. cit., passim, esp. 120-125; 140-147; Maarten den Heijer y Rick Lawson, "Extraterritorial Human Rights and the Concept of Jurisdiction'", en: Ibidem, esp.172-182; Cedric Ryngaert, "Jurisdiction", en: Ibidem., passim; August Reinisch, "Aid or Assistance and Direction and Control between States and International Organizations in the Commission of Internationally Wrongful Acts", en: 7 International Organizations Law Review, 2010, 63-77, passim; Paul De Hert y Fisnik Korenica, "The Doctrine of Equivalent Protection: Its Life and Legitimacy Before and After the European Union's Accession to the European Convention on Human Rights", en: 7 German Law Journal, 2012, vol. 13, 874-895.
} 
derechos humanos si el/la actor/a tiene efectivamente "el control". Sin embargo, en varios casos, aunque no exclusivamente, estos esfuerzos se han efectuado en contextos de vulneraciones de derechos civiles y políticos, del derecho internacional humanitario, del derecho penal internacional y de las "partes duras" del derecho internacional general, como el deber de respetar la integridad territorial de los Estados. No será fácil aplicarlos —de forma acumulativa- en contextos: a) de vulneración de los derechos económicos, sociales y culturales; b) que tienen lugar extraterritorialmente, por y a través de c) los canales de las IFI y/o sus Estados miembros. En algunas situaciones y casos, no sería muy difícil de lograr: es posible pensar en la construcción de la típica represa financiada por el Banco Mundial que lleva al desalojo forzoso de una comunidad indígena local (fenómeno también llamado "aldeización" ${ }^{69}$ y que comprendería una cantidad de vulneraciones a los derechos humanos, entre ellos, los económicos, sociales y culturales en función de la situación concreta de que se trate. No obstante, estos ejemplos suelen ser demasiado sencillos y no del todo apropiados para seguirlos al pie de la letra en situaciones menos claras.

Más evidente aún es un caso como el anterior si agregamos al espectro los matices del tema de la "causalidad de las violaciones de los derechos humanos”. ¿En qué circunstancias puede hablarse de un vínculo causal suficiente entre la actividad de una IFI o de un Estado miembro y una vulneración específica de los derechos humanos para considerar a ese actor responsable de tal vulneración? O lo que es más difícil aún: la relación entre la omisión de actuar y el no prevenir las vulneraciones graves. Una vez más, en algunos casos podría ser posible establecer tales vínculos y los desalojos forzosos mencionados pueden servir de ejemplo posible, aunque incluso allí dependerá de los hechos exactos del caso si el actor podría reclamar o no la presencia de circunstancias que excluyeran el accionar

69 Para el caso mencionado, ver por ejemplo, Human Rights Watch, op. cit., passim. 
indebido (cf. el capítulo V del Proyecto de Artículos sobre la Responsabilidad del Estado por Hechos Internacionalmente Ilícitos). Sigrun Skogly ha observado lo difícil que es determinar la causalidad en el contexto de las obligaciones relativas a los derechos humanos extraterritoriales. Así, la autora identifica dos tipos de "obstáculos": "En primer lugar, la determinación de qué actos y omisiones condujeron realmente a resultados que pueden clasificarse como violaciones de derechos humanos y, en segundo lugar, la identificación de requisitos legales internacionales que puedan convertir esos actos y omisiones en ilícitos". ${ }^{70}$ Si se tienen en cuenta esas cuestiones jurídicas clave en el contexto de la labor de las IFI y se consideran (las interacciones entre) las obligaciones analizadas en el apartado 3, es claro que no será fácil establecer un estándar de control factible en todas y cada una de las situaciones a las que deban enfrentarse las IFI y sus Estados miembros en el contexto del esbozo y la ejecución de sus políticas, programas y proyectos. Pero ya sea que se tenga un estándar tan integral y abarcador como si no, de todas formas se necesitaría un análisis caso por caso para establecer el grado exacto de control y las responsabilidades correspondientes. Estoy de acuerdo con lo observado por Martin Scheinin en más de una ocasión en cuanto a que "la facticidad crea normatividad", lo que significa que la "evaluación contextual de las circunstancias fácticas" 71 de un caso o situación debe guiar el análisis para la determinación de la jurisdicción y sus consecuencias. Y un enfoque así, caso por caso, no debe emprenderse sin orientación. A fin de cuentas, solo se trata de demostrar suficientes vínculos fácticos entre la decisión y los resultados (negativos), lo cual será llevado adelante por terceros independientes (tribunales,

\footnotetext{
70 Sigrun Skogly, "Causality and Extraterritorial Human Rights Obligations", en Malcolm Langford, Wouter Vandenhole, Martin Scheinin y Willem van Genugten (eds.), op. cit., 235.

71 Martin Scheinin, "Just Another Word? Jurisdiction in the Roadmaps of State Responsibility and Human Rights", en Malcolm Langford, Wouter Vandenhole, Martin Scheinin y Willem van Genugten (eds.), op. cit., 212.
} 
comités, comisiones de investigación) que arriben a resultados justificables y razonables. Aquí es posible hacer referencia a la "prueba de razonabilidad" de Cedric Ryngaert, inspirada en las normas de hechos ilícitos extracontractuales de los Estados Unidos. ${ }^{72}$ Si combinamos las perspectivas de Skogly, Scheinin y Ryngaert, estamos en condiciones de analizar y juzgar situaciones concretas, efectuadas, inspiradas y dirigidas en función de las obligaciones relativas a los derechos humanos de los actores involucrados y del sistema de atribución de conductas ilícitas tal como se desarrolla en el contexto del Proyecto de Artículos sobre la Responsabilidad de los Estados por los Actos Internacionalmente Ilícitos y del PAROI; y, a la vez, tendremos un terreno más especificado por órganos clave legales y semilegales dotados de autoridad legal y semilegal. Si esta labor de juzgar y analizar fuera realizada por expertos/as independientes en materia de derechos humanos, cualquiera fuese el marco de su accionar (como se señaló: tribunales, comités, comisiones de investigación) y, de ser pertinente, en interacción con otras disciplinas (economía, finanzas, antropología), podremos confiar en que también en el contexto de las IFI veremos avances como los que se analizan en este artículo.

\subsection{Responsabilidad principal, subsidiaria y compartida}

Como se ha observado, existe un vínculo directo entre "tener control" - lo que incluye determinar los vínculos causales entre la decisión y el resultado-, atribuir al actor/a en cuestión una conducta que infringe el derecho internacional de los derechos humanos y establecer la responsabilidad correspondiente. El mismo razonamiento puede aplicarse cuando la IFI y el Estado miembro no actúan por separado sino en conjunto. En ese caso, (tendrán que) enfrentar las consecuencias de su responsabilidad compartida, establecida a través de los procedimientos bosquejados precedentemente, que llevan a

72 Cedric Ryngaert, op. cit., especialmente 198. 
asignar la responsabilidad según el peso relativo del accionar (no) realizado y de las violaciones cometidas.

Las reglas del PAROI y su Comentario trazan una distinción entre la invocación de responsabilidad principal y subsidiaria y la invocación de la responsabilidad mancomunada y solidaria. El primero de estos casos, en mi opinión, consiste más bien en una cuestión de dividir responsabilidades y tener un resguardo en caso de que falle la invocación de responsabilidad principal; el segundo se relaciona con lo que en el presente artículo y en otros contextos se denomina "responsabilidad compartida". Respecto de lo primero, el PAROI establece que "[c]uando una organización internacional y uno o varios Estados [...] [u] otras organizaciones internacionales sean responsables del mismo hecho internacionalmente ilícito, podrá invocarse la responsabilidad de cada Estado u organización en relación con ese hecho" (artículo 48, párrafo 1); y también estipula que esa responsabilidad "solo podrá invocarse en la medida en que la invocación de la responsabilidad principal no haya dado lugar a reparación" (artículo 48, párrafo 2). La responsabilidad principal podría relacionarse con las IFI o también con los Estados miembros, lo que dependerá de la política, el programa o el proyecto en cuestión. En cuanto a la obligación correspondiente de reparación, el Comentario de la CDI agrega que habrá "casos en que un Estado o una organización internacional asuma solo una responsabilidad subsidiaria, en el sentido de que estará obligado a dar reparación únicamente si el Estado o la organización internacional principalmente responsable no la presta, y solo en esa medida". ${ }^{73}$ Las palabras son conceptualmente muy claras.

Respecto de la responsabilidad compartida, el Comentario a las reglas del PAROI afirma sin demasiada especificidad: "[1]a aceptación de responsabilidad por un Estado puede entrañar una responsabilidad subsidiaria o una responsabilidad mancomunada y solidaria"; y añade: "lo mismo cabe decir de la

73 Comentario, op. cit., 77. 
responsabilidad fundada en la confianza [...] [p]or regla general, solo se puede enunciar una presunción simple". ${ }^{74}$ En línea con las aseveraciones de Ashfaq Khalfan e Ian Seiderman, como se argumentara en apartados anteriores, coincidiré en cuanto a que "el principio de responsabilidad mancomunada no se aplica a un Estado que puede demostrar que ha tomado todas las medidas razonables para asegurar los derechos humanos en conductas que tienen efectos más allá de las fronteras ${ }^{75}$ ". Si bien esta observación hace referencia a la responsabilidad mancomunada de Estados en un accionar extraterritorial, el mismo razonamiento puede aplicarse a las responsabilidades compartidas por un Estado y una IFI. El "objetor persistente", concepto desarrollado en el contexto del derecho internacional consuetudinario pero también útil por analogía en esta coyuntura, no puede ser inculpado por la conducta si efectivamente ha tomado todas las medidas razonables para evitarla.

Entonces surge la pregunta de si los conceptos discutidos en el apartado 4.2 (en cuanto a tener "control") son adecuados y suficientes para abordar también todos los aspectos de la atribución de "responsabilidad compartida". Si se mide el grado de control de cada actor de manera individual, se podría concluir o que hay una superposición en la atribución de conductas a cada uno, o que hay una brecha en dicha atribución. Podría suceder también que un actor se escondiera detrás del otro, con el subsiguiente riesgo de que no se asignen responsabilidades principales, subsidiarias o compartidas por la conducta indebida y de que no se otorgue la reparación adecuada a las víctimas, cualquiera sea su forma. Coincido con lo expuesto por Wouter Vandenhole en cuanto a que quizás sean necesarios conceptos como el de "complicidad". ${ }^{76}$ Vanderhole observa que, en el

\footnotetext{
74 Ibidem, 99.

75 A Ashfaq Khalfan e lan Seiderman, op. cit., 27.

76 W. Vandenhole, 2015, op. cit. También es posible consultar las complejidades que se analizan en esta fuente al introducir el término en otro contexto diferente del habitual.
} 
ámbito internacional, el término se usa en el marco de obligaciones directas que tienen las empresas en materia de derechos humanos ("complicidad corporativa"), pero que también es posible referirse al ámbito del derecho penal internacional y a conceptos como el de "empresa criminal conjunta". En ambos contextos, estas palabras tienen un significado específico de por sí, mientras que la aplicación del concepto compuesto por capas - por ejemplo, "complicidad directa, indirecta y silenciosa”, que también analiza Vandenhole- arrojará resultados específicos según el contexto nuevo al que se lo aplique. De todas maneras, no hay dudas en cuanto al aspecto clave: en el caso de acciones conjuntas que infrinjan cualquier parte del derecho internacional de los derechos humanos, se necesitan conceptos que aborden la cuestión de las responsabilidades superpuestas y compartidas. Y si bien se autoriza a los antes mencionados "(terceros) órganos independientes" a que realicen análisis y pronunciamientos sobre situaciones y casos concretos, a la hora de ponderar toda la información y de asignar responsabilidades adecuadamente, como ya se ha señalado, serán relevantes los criterios desarrollados en la sección sobre "tener control".

En todos los casos, la conclusión es que, conforme al actual derecho internacional de los derechos humanos, la responsabilidad de no causar daño en dichos términos, de observar activamente la normativa en la materia según la tipología tripartita principal y de tomar medidas correctivas eficaces en el caso de incumplimiento, concierne a todos los actores cuyas actividades afectan de hecho la vida de las personas. Si se tienen en cuenta todas las dificultades que enfrentan las IFI, un enfoque realista para la determinación del grado de control y de las responsabilidades correspondientes inevitablemente tendrá que conllevar también -y estoy convencido de que en los hechos así será- a la aceptación de estas responsabilidades. 


\section{Conclusiones}

En los últimos veinte años se han publicado numerosos estudios sobre la forma en que ambas IFI han asumido las obligaciones de derechos humanos o se han abstenido de hacerlo. El presente artículo podría haber puesto más alta la vara de las obligaciones legales estrictas y de las responsabilidades correspondientes para ambas IFI, por ejemplo, mediante interpretaciones más extensas de la jurisprudencia existente, o mediante una extrapolación más progresiva de las tendencias en el campo de los derechos humanos. Sin embargo, en mi opinión, presentar el artículo de esa manera habría sobreextendido la validez jurídica y la aplicabilidad de los desarrollos en el ámbito del derecho internacional de los derechos humanos a ambas IFI. En cambio, el artículo tomó tres direcciones: identificando primero lo que ya sucede dentro de ambas IFI en términos (del derecho) de los derechos humanos; seguido por un abordaje del derecho existente en el campo de los derechos humanos y una "localización" de dicho derecho dentro los mandatos de las IFI; y discutiendo una serie de temas relevantes para una comprensión realista de la responsabilidad principal, subsidiaria o compartida que las IFI tendrán que enfrentar en caso de que su conducta cause, de una forma u otra, violaciones a los derechos humanos.

En líneas generales, existen presiones considerables sobre ambas organizaciones $\mathrm{y}$, mutatis mutandis, sobre otros bancos multilaterales de desarrollo no mencionados en este artículo, para que asuman más responsabilidad en virtud de los estándares internacionales en materia de derechos humanos. En el presente artículo se ha dejado en claro, dado el estado del arte del derecho internacional de los derechos humanos al año 2014, qué estándares sí son aplicables a las IFI. Al mismo tiempo, si bien en diferente grado, ambas IFI aún argumentan que no están sujetas a esas normas, queda demostrado que el espacio para esos argumentos es cada vez más limitado. Con este análisis, en mi opinión, se contribuye a destacar que ambas IFI se encaminan, de a (pequeños) pasos, a reconocer la pertinencia 
de los derechos humanos para el cumplimiento de sus mandatos, incluso, aún si uno/a acepta que sus pronunciamientos son solo parcialmente pertinentes desde el punto de vista legal y, lo que es más importante, que el presente artículo no refiere a la aplicación de sus afirmaciones en la práctica diaria. Es mejor considerar al derecho internacional de los derechos humanos como una forma de derecho vivo, y a los actores involucrados, como las IFI, entidades no estáticas, aun cuando tengan abordajes estáticos, por momentos, de sus propios mandatos. Aunque en diferente grado, ambas IFI han atravesado el umbral de los derechos humanos. Si quisieran retroceder o reconsiderar cómo seguir adelante, el estado del arte en el derecho international de los derechos humanos al año 2014 podrá darles luz verde o bien actuar como señal de detención. 